\title{
Mengukur Kinerja Pasar melalui Elemen Inovasi pada UKM Sektor Makanan dan Minuman di Kota Padang
}

\author{
Alvi Syukri Faisal ${ }^{1 *}$, Ma'ruf ${ }^{1}$, Ratni Prima Lita ${ }^{1}$, Tedi Hidayat ${ }^{2}$ \\ ${ }^{1}$ Program Magister, Fakultas Ekonomi dan Bisnis, Universitas Andalas, Padang, \\ Indonesia \\ ${ }^{2}$ Praktisi Ekonomi, Inkubator Bisnis dan Teknologi, Karajoelok.com, Padang, \\ Indonesia \\ *alvi.syukri.faisal08@gmail.com
}

\begin{abstract}
In Small and Medium Enterprises (SMEs), especially in the food and beverage sector, process innovation is an important construct that can maintain the sustainability of product innovation and improve marketing innovation strategies for optimal market performance. This study aims to examine the effect of innovation elements, namely product, process, and marketing on the market performance of SMEs in the food and beverage sector, and the effect of marketing innovation on market performance when mediated by product innovation. Using a purposive sampling technique with the criteria of SMEs in the food and beverage sector that is not a franchise. A total of 104 feedback questionnaires was analyzed using the SmartPLS 3.3 software and Microsoft Excel. This study found that all hypotheses were supported significantly in a positive relationship.
\end{abstract}

Keywords: Marketing Innovation, Market Performance, Process Innovation, Product Innovation

\section{PENDAHULUAN}

Era globalisasi semakin memudahkan akses konsumen dalam membandingkan suatu produk atau jasa (Desara et al., 2021), telah memberikan tantangan baru bagi pelaku usaha, baik itu menengah ke atas maupun menengah ke bawah (Lestari et al., 2018). Iddris (2019) menyatakan kemudahan akses yang dimiliki konsumen dalam era digital membuat mereka lebih sensitive dengan produk. Sedangkan Hajduova et al. (2021) menyatakan bahwa untuk memenuhi kebutuhan dan keinginan konsumen pelaku usaha diharuskan untuk melakukan inovasi terhadap produknya dengan proses yang cepat dan higenis, setelah itu memasarkannya dengan cara-cara yang inovatif, kreatif dan terkini (Biégas, 2018).
Industri makanan dan minuman adalah contoh bagaimana perkembangan ilmu pengetahuan dapat dengan begitu cepat memanifestasikan dirinya pada perubahan teknologi dalam produksi dan konsumsi (Triguero et al., 2018), karena perubahannya seringkali berbasis teknologi daripada berbasis sains (Garcia Martinez \& Briz, 2000). Laju perubahan teknologi dalam usaha makanan dan minuman hanya diukur dengan jumlah penemuan yang dipatenkan (Adnan \& Ahmad, 2015), yang mana menjadi tidak seimbang dengan sektor lain yang dapat diukur pada tingkatan eksperimental (Elgebali, 2019; Usmed et al., 2021), sementara ditengah pandemi Covid-19 ekonomi dalam arah negatif dan persaingan bisnis semakin kompetitif (Hidayat et al., 2021) sehingga menuntut UKM untuk 
mengembangkan inovasi dan mengimplementasikannya.

Inovasi memberikan dampak yang besar terhadap tingkat persaingan bisnis (Hamali, 2015), sensitifitas konsumen terhadap suatu produk makanan dan minuman akan berdampak pada persaingan pasar yang sangat ketat (Putri \& Yasa, 2018), dan ekspektasi pasar yang tinggi (Chi \& Seockjin, 2017; Zhang et al., 2013). UKM makanan dan minuman melakukan inovasi agar dapat meraih pangsa pasar yang lebih luas dan penjualan yang maksimal (Bresciani, 2017).

Pada konteks ini, UKM di Kota Padang memang belum sepenuhnya menerapkan konsep inovasi dalam usahanya (Lita et al., 2018), sehingga masih sedikitnya produk baru di pasar (Pratama et al., 2021), kejenuhan pembeli dan pengunjung dipicu oleh inovasi pelaku UKM yang menampilkan produkproduk yang sama dari tahun ke tahun (Games et al., 2020). Hal ini menyiratkan bahwa penerapan strategi inovasi dalam produk dan pemasaran yang masih langka dan tradisional, serta inovasi proses yang belum memenuhi standar dan masih buruk.

Inovasi pemasaran memainkan peran penting dalam mengamankan loyalitas pelanggan dan meningkatkan keberhasilan inovasi produk (Ndiaye et al., 2018). Sedangkan, inovasi produk lebih kepada efektifitas dalam mencapai tujuan untuk mengembangkan, dan menunaikan tawaran baru, dan bukan pada arah efesiensi (Maisont et al., 2020), karena produk baru seringkali mensyaratkan dan menuntut tambahantambahan pada lini sumberdaya, pergantian proses-proses produksi, hingga memaksa pada prosedur-prosedur baru (Kahn, 2018).

Inovasi proses dapat menjaga keberlanjutan produk yang diinovasikan, serta memberikan dorongan pada peningkatkan strategi untuk inovasi pemasaran (Werker, 2003). Sebagai contoh, pemahaman inovasi pemasaran dapat mendorong inovasi produk dan kinerja pasar UKM melalui informasi-informasi permintaan konsumen (Aksoy, 2017). Secara keseluruhan, aktifitas inovasi memberikan UKM alat-alat untuk mempersingkat product life cycle dan meningkatkan kemampuan mereka dalam mempertahankan usahanya (Chen, 2006), terutama pada bisnis kecilmenengah di sektor makanan dan minuman (Grashuis \& Dary, 2019).

Terdapat beberapa alasan penting mengarahkan penelitian ini pada UKM, dimana UKM memainkan peran vital dalam pengembangan ekonomi yang berkelanjutan, kesejahteraan, dan pertumbuhan pendapatan diseluruh dunia (Erdin \& Ozkaya, 2020). Di Indonesia, sektor UKM tercatat telah menjadi penyumbang produk domestik bruto sekitar 60\% (Pratama et al., 2021; Kemenkop UKM, 2021), sebelumnya sektor ini juga telah menyelamatkan Bangsa Indonesia dari keterpurukan dalam krisis ekonomi pada tahun 1997/1998. Lebih jauh lagi, UKM juga membantu menekan angka pengangguran, dan menciptakan lingkungan yang lebih dinamis dalam situasi kedaruratan ekonomi (Lita et al., 2018), serta pariwisata daerah sekitarnya (Games et al., 2020).

Para Aktor-aktor UKM di sektor makanan dan minuman seharusnya mengedepankan sesuatu yang berbeda untuk mencapai keunggulan bersaing yang berkelanjutan (Seyfettinoğlu, 2016), agar dapat memaksimalkan kinerja pasarnya (Ahmadi \& O'Cass, 2016). Kinerja pasar UKM disektor makanan dan minuman yang meningkat adalah bukti dari keberhasilan strategi dari aktor UKM untuk bertahan dan memperluas pangsa pasar mereka (RoucanKane et al., 2011). Penelitian Abdilahi et al. (2017) dan Aksoy (2017) menemukan bahwa pengaruh yang signifikan dan positif dari inovasi pemasaran pada kinerja pasar pada UKM, khususnya di sektor makanan dan minuman (Adnan \& Ahmad, 2015; Grashuis \& Dary, 2019).

$\mathrm{H}_{1}$ : Inovasi pemasaran berpengaruh positif dan signifikan pada kinerja pasar

Ramirez et al. (2018) menyatakan inovasi pemasaran memberikan keunggulan kompetitif yang berkelanjutan, karena mengubah kebiasaan lama menjadi baru (Saunila, 2017). Inovasi pemasaran bertujuan untuk terhubung dengan pelanggan dan 
konsumen di tingkat yang baru dan berbeda hingga dapat mencakup jenis upaya promosi baru (Oh et al., 2015). Aksoy (2017) telah membuktikan bahwa inovasi pemasaran berpengaruh positif dan signifikan pada inovasi produk.

$\mathrm{H}_{2}$ : Inovasi pemasaran berpengaruh positif dan signifikan pada inovasi produk

Demi tercapai inovasi produk yang diminati pasar, pelaku UKM harus melakukan inovasi dalam proses-proses operasi, baik itu alat, metode, ataupun bahan-bahan dasar dari produk (Fortuin \& Omta, 2009), karena inovasi proses sangat penting diperhatikan dalam kesuksesan inovasi produk (Abdilahi $e t$ al., 2017), serta berkaitan dengan efisiensi dan kecepatan waktu dalam merilis produk (Lita et al., 2018).

$\mathrm{H}_{3}$ : Inovasi proses berpengaruh positif dan signifikan pada inovasi produk

Kemajuan teknologi saat sekarang telah membiasakan perilaku konsumen kearah transaksi digital harus mendapat perhatian serius oleh aktor-aktor UKM (Tutar et al., 2015), mereka dengan mudah untuk membandingkan citra rasa dan harga produk dengan produk lain (Rahmawati et al., 2019). Kumpulan informasi konsumen yang didapatkan melalui inovasi pemasaran dan teknologi pemasaran telah memungkinkan pelaku UKM untuk menjangkau konsumen menjadi lebih luas dan efektif (Chen, 2019), serta dapat memenuhi kebutuhan konsumen melalui penetapan harga yang optimal (Gotteland et al., 2020).

Penelitian Grimpe et al. (2017), menemukan bahwa peran inovasi pemasaran didorong oleh sejauhmana produk-produk diinovasikan hingga memberikan dampak pada kinerja pasar yang optimal, dan membangun terciptanya loyalitas serta kepercayaan dari pelanggan (Grimpe et al., 2017). Abdilahi et al. (2017) juga menyatakan bahwa inovasi pemasaran mendorong inovasi produk secara signifikan dikarenakan informasi tentang permintaan serta saran mereka. Lebih jauh lagi, Adnan dan Ahmad, (2015) serta Bresciani (2017) menemukan bahwa inovasi produk berpengaruh signifikan dalam menjaga kinerja pasar maksimal pada UKM di sektor makanan dan minuman.

$\mathrm{H}_{4}$ : Inovasi produk berpengaruh positif dan signifkan pada kinerja pasar

$\mathrm{H}_{5}$ : Inovasi pemasaran berpengaruh positif dan signifikan pada kinerja pasar ketika dimediasi oleh inovasi produk

\section{METODE}

Penelitian ini dilakukan menggunakan pendekatan kuantitatif dengan jenis eksplanatory research. Pada pengambilan sampel, digunakan teknik purposive sampling, dan dalam penentuan jumlahnya penulis mengacu pada formulasi Hair et al. (2010) untuk populasi yang tidak diketahui. Kriteria sampel yang ditetapkan yaitu pelaku UKM sektor makanan dan minuman yang bukan frienchise. Selanjutnya, kuisioner online dengan skala likert (mulai 1 yang menunjukkan sangat tidak setuju sampai dengan 5 yang menunjukkan sangat setuju), dibagikan menggunakan bantuan aplikasi google questionnaire untuk meminimalisir resiko penyebaran Covid-19 serta alasan efesiensi waktu dan biaya dalam melakukan penelitian. Sehubungan dengan itu,

Perilaku pelaku UKM makanan dan minuman yang begitu terdampak akibat Covid-19 tidak sepenuhnya koorporatif dengan penelitian ini. Sehingga hanya diterima sebanyak 115 feedback kuisioner, dan hanya 104 yang dapat dilakukan pada tahap analisis deskriptif dan SEM-PLS. Jumlah 104 dianggap cukup untuk penggunaan SEM-PLS sebagaimana Hair et al. (2010) jelaskan bahwa dibutuhkan sampel minimal berkisar antara 100-300 dalam pendugaan SEM. Byrne (2009) juga merekomendasikan sampel minimal yang dapat diterima untuk estimasi SEM ialah 100. PLS-SEM sangat baik digunakan ketika ukuran sampel kecil (Hair et al., 2017; Reinartz et al., 2009). Pengujian analisis SEM-PLS juga didasari oleh keunggulannya dalam analisis multivariate dan lebih mudah secara operasional penggunaan serta diterjemahkan (Hult et al., 2015). 
Analisis deskriptif dilakukan menggunakan metode distribusi frekuensi. Sehubungan dengan itu, nilai total capaian responden (TCR) dihitung mengacu pada Sugiyono (2010), dengan formulasi sebagai berikut:

$$
\mathrm{TCR}=R \mathrm{~s} / \mathrm{n}(\mathrm{x} 100)
$$

Ket: $\mathrm{TCR}=$ total capaian responden

$R \mathrm{~s}=$ rata-rata skor tanggapan

$\mathrm{N}=$ nilai skor jawaban

Sedangkan pada SEM-PLS, uji prasyarat dilakukan pada tahap awal untuk memastikan apakah data dapat diteruskan pada uji hipotesis (Hult et al., 2015). Menurut Hair et al. (2010), nilai AVE > 0,5 dan lolos uji validitas diskriminan merupakan syarat uji validitas, sedangkan prasyarat uji reliabilitas adalah ketika nilai cronbach alpha dan composite reliability > 0,7 (Hair et al., 2010). Kemudian, untuk uji hipotesis, pengaruh variabel prediktor pada variabel outcome dinyatakan signifikan apabila nilai $t$-value nya $\geq 1,64$ untuk one-tail test, dan nilai $p$-value nya $\leq$ 0,05 (Hair et al., 2010; Hult et al., 2015).

\section{HASIL DAN PEMBAHASAN Indentitas Responden}

Penggolongan yang dilakukan terhadap responden dalam penelitian ini bertujuan untuk mengetahui secara jelas mengenai gambaran umum identitas responden yang berpartisipasi, yang mana penetapannya didasari oleh kebutuhan penelitian. Tabel 1 menjelaskan secara rinci tentang informasi tersebut. UKM sektor makanan dan minuman di Kota Padang mengalami penurunan dalam hal pendapatan perbulannya, dibuktikan dengan pendapatan mayoritas kurang dari Rp30 juta, angka ini terbilang jauh dibawah standar minimal pendapatan UKM perbulannya.
Tabel 1. Identitas Responden

\begin{tabular}{|c|c|c|}
\hline Karakteristik & Jumlah & $\%$ \\
\hline \multicolumn{3}{|l|}{ Jenis Kelamin } \\
\hline Laki - Laki & 46 & 44,2 \\
\hline Perempuan & 58 & 65,8 \\
\hline \multicolumn{3}{|l|}{ Usia } \\
\hline$\leq 20$ & 4 & 3,84 \\
\hline $21-30$ & 61 & 58,65 \\
\hline $31-40$ & 30 & 28,84 \\
\hline$>40$ & 9 & 8,67 \\
\hline \multicolumn{3}{|l|}{ Pendapatan } \\
\hline$<\operatorname{Rp} 10.000 .000$ & 44 & 42,3 \\
\hline Rp 10.000.001-30.000.000 & 39 & 26,83 \\
\hline Rp 30.000.001-60.000.000 & 6 & 5,76 \\
\hline > Rp 60.000.001 & 11 & 10,57 \\
\hline \multicolumn{3}{|l|}{ Pemodalan } \\
\hline Modal Pribadi & 58 & 55,76 \\
\hline Modal Keluarga & 22 & 21,15 \\
\hline Modal Gabungan & 18 & 17,3 \\
\hline $\begin{array}{c}\text { Modal Gabungan }+ \text { Bank } \\
\text { Jenis UKM }\end{array}$ & Jenis UKM & 5,76 \\
\hline Makanan & 66 & 63,4 \\
\hline Minuman & 38 & 36,6 \\
\hline \multicolumn{3}{|l|}{ Lama Usaha } \\
\hline$<1$ tahun & 20 & 19,23 \\
\hline 1-5 tahun & 33 & 31,73 \\
\hline 5-10 tahun & 27 & 25,96 \\
\hline$>10$ tahun & 24 & 23,08 \\
\hline & $\mathrm{n}=104$ & \\
\hline
\end{tabular}

Responden penelitian ini didominasi oleh perempuan yang berusia tergolong muda. Mereka kebanyakan bergerak dibidang makanan yang merupakan salah satu kebanggan masyarakat Kota Padang, dan mayoritas pelaku UKM pada sektor makanan dan minuman ini telah beroperasi lebih dari satu tahun.

\section{Analisis Deskriptif}

Analisis deskriptif dilakukan untuk melihat tanggapan responden terhadap indikator-indikator dalam masing-masing variabel (Sugiyono, 2010). Sehubungan dengan itu, total capaian responden (TCR) atas pernyataan penelitian dikategorikan dalam 5 tingkatan dengan rentang nilai: " $84 \%-100 \%$ termasuk kategori sangat tinggi, $68 \%-84 \%$ tinggi, $52 \%$ - $68 \%$ cukup, $36 \%$ $52 \%$ rendah, dan 0-36 \% termasuk dalam kategori yang sangat rendah (Sugiyono, 2010). 
Tabel 2. Kinerja Pasar

\begin{tabular}{lcc}
\hline \multicolumn{1}{c}{ Pernyataan } & TCR & Kategori \\
\hline $\begin{array}{l}\text { Inovasi yang kami lakukan } \\
\text { telah menarik banyak } \\
\text { pelanggan baru. }\end{array}$ & $84 \%$ & Sangat Tinggi \\
$\begin{array}{l}\text { Kami merasa dengan ber- } \\
\text { inovasi cakupan pemasaran } \\
\text { menjadi lebih luas. }\end{array}$ & $86 \%$ & Sangat Tinggi \\
$\begin{array}{l}\text { Kami merasa inovasi yang } \\
\text { kami lakukan membuat } \\
\text { penjualan meningkat. }\end{array}$ & $86 \%$ & Sangat Tinggi \\
$\begin{array}{l}\text { Kami merasa telah } \\
\text { mengamankan pangsa pasar } \\
\text { yang diinginkan. }\end{array}$ & $80 \%$ & Tinggi \\
$\begin{array}{l}\text { Secara keseluruhan, kami } \\
\text { berhasil mencapai kinerja } \\
\text { pasar yang memuaskan. }\end{array}$ & $84 \%$ & Sangat Tinggi \\
\hline
\end{tabular}

Pada kinerja pasar, responden mengakui bahwa dengan berinovasi akan memperluas cakupan pemasaran, dan inovasi juga diakui telah membuat penjualan meningkat, hal ini dibuktikan oleh nilai TCR pada pernyataan-pernyataan tersebut yang termasuk dalam kategori sangat tinggi. Sementara itu, pernyataan bahwa pelaku UKM pada sektor makanan dan minuman di Kota Padang telah mengamankan pangsa pasar mereka, memperoleh nilai TCR $80 \%$ adalah yang terrendah dari semua indikator yang diusulkan dalam variabel kinerja pasar.

Hasil ini mengindikasikan bahwa persaingan terus meningkat dan semakin ketat, karena kemudahan akses digital dan penggunaannya membuat para pelaku tidak begitu yakin apakah mereka telah mengamankan pangsa pasar mereka setelah mereka melakukan inovasi. Hal ini juga mengindikasikan kerentanan posisi bisnis yang dapat berubah begitu cepat, baik itu naik atau turunnya kinerja pasar mereka.

Tabel 3. Inovasi Pemasaran

\begin{tabular}{lcc}
\hline \multicolumn{1}{c}{ Pernyataan } & TCR & Kategori \\
\hline $\begin{array}{l}\text { Kami menginovasikan program } \\
\text { pemasaran kami untuk tetap } \\
\text { menjadi yang terdepan di pasar }\end{array}$ & $86 \%$ & Sangat tinggi \\
$\begin{array}{l}\text { Kami mencoba menemukan } \\
\text { cara baru untuk membangun } \\
\text { dan meningkatkan hubungan } \\
\text { dengan pelanggan. }\end{array}$ & $89 \%$ & Sangat tinggi \\
$\begin{array}{l}\text { Teknik penjualan selalu kami } \\
\text { tingkatkan dengan mencoba } \\
\text { untuk menemukan metode baru }\end{array}$ & $85 \%$ & Sangat tinggi \\
$\begin{array}{l}\text { Kami menerapkan program } \\
\text { pemasaran yang inovatif. }\end{array}$ & $83 \%$ & Tinggi
\end{tabular}

\begin{tabular}{lcc}
\hline \multicolumn{1}{c}{ Pernyataan } & TCR & Kategori \\
\hline $\begin{array}{l}\text { Kami mencari cara untuk } \\
\text { mengembangkan model bisnis } \\
\text { baru. }\end{array}$ & $84 \%$ & Sangat Tinggi \\
$\begin{array}{l}\text { Desain produk terus diperbarui } \\
\text { sesuai dengan kebutuhan } \\
\text { pelanggan dan produk }\end{array}$ & & \\
$\begin{array}{l}\text { kompetitif kami. } \\
\text { Kami mencari cara yang } \\
\text { inovatif untuk alat dan metode } \\
\text { promosi dalam meningkatkan } \\
\text { cakupan promosi. }\end{array}$ & $84 \%$ & Sangat Tinggi \\
\hline
\end{tabular}

Pada inovasi pemasaran, nilai TCR tertinggi menyatakan bahwa pelaku UKM makanan dan minuman terus mencoba menemukan cara baru untuk meningkatkan hubungan dengan pelanggan. Hal ini mengindikasikan bahwa ditengah ketatnya persaingan dan keinginan para pelaku untuk tetap unggul dan kompetitif, telah mendorong mereka untuk terus mencari cara supaya pelanggan mereka tetap loyal dan calon pelanggan mereka menjadi lebih tertarik dengan cara-cara yang inovatif dan sesuai harapan pelanggan. Sementara itu, nilai TCR terrendah menyatakan bahwa pelaku UKM makanan dan minuman menerapkan pemasaran yang inovatif.

Temuan ini, mengisyaratkan bahwa para pelaku UKM yang bergerak dibidang makanan dan minuman di Kota Padang, belum sepenuhnya menerapkan inovasi dalam pemasaran, beberapa dari mereka masih mempertahankan cara-cara lama yang telah terbukti sebelumnya dan mereka yakini akan dapat digunakan pada saat sekarang. Hal ini sangatlah wajar dikarenakan tidak semua pelaku UKM pada sektor makanan dan minuman memahami tentang dampak dari inovasi pemasaran yang hampir sepenuhnya mengarah pada digital dan teknologi.

Tabel 4. Inovasi Proses

\begin{tabular}{lcc}
\hline \multicolumn{1}{c}{ Pernyataan } & TCR & Kategori \\
\hline $\begin{array}{l}\text { Kami mempelajari tentang } \\
\text { inovasi-inovasi proses yang } \\
\text { sedang berkembang. }\end{array}$ & $88 \%$ & Sangat Tinggi \\
$\begin{array}{l}\text { Kami lebih memprioritaskan } \\
\text { penerapan inovasi proses } \\
\text { terbaru. }\end{array}$ & $83 \%$ & Tinggi \\
$\begin{array}{l}\text { Kami mengikuti } \\
\text { perkembangan inovasi proses } \\
\text { terbaru. }\end{array}$ & $83 \%$ & Tinggi
\end{tabular}




\begin{tabular}{lcc}
\hline \multicolumn{1}{c}{ Pernyataan } & TCR & Kategori \\
\hline $\begin{array}{l}\text { Kami memperkenalkan } \\
\text { inovasi proses yang sangat } \\
\text { berbeda dari proses yang ada. }\end{array}$ & $81 \%$ & Tinggi \\
\hline
\end{tabular}

Pada inovasi proses, para pelaku UKM makanan dan minuman masih berada pada taraf mempelajari tentang inovasi-inovasi terkait proses yang sedang berkembang, ini dibuktikan dengan nilai TCR yang tertinggi. Sedangkan nilai TCR terrendah, menyatakan bahwa para pelaku UKM sektor makanan dan minuman memperkenalkan inovasi proses yang sangat berbeda dari proses yang ada.

Berkaitan dengan temuan deskriptif tersebut, dapat disimpulkan bahwa tingginya kemauan pelaku UKM pada sektor makanan dan minuman di Kota Padang untuk naik kelas untuk meningkatkan penjualan serta memperluas pangsa pasar mereka, mendorong mereka untuk terus mempelajari tentang inovasi-inovasi proses yang sedang berkembang. Saat ini, belum sepenuhnya pelaku menggunakan inovasi dalam prosesprosesnya, karena mereka masih berada pada taraf pembelajaran dan memahami lebih dalam terkait inovasi dari proses-proses usaha mereka.

Pada inovasi produk, pernyataan dengan nilai TCR tertinggi mengisyaratkan keyakinan dan kesadaran para pelaku bahwasannya dengan produk-produk baru mereka akan dapat menembus pasar sasaran dengan efektif. Menurut Analisa penulis, hal ini dilakukan karena tuntutan persaingan yang semakin kompetitif di pasaran serta pertumbuhan ekspektasi konsumen terkait produk-produk baru. Sedangkan nilai TCR terrendah mengindikasikan bahwa para pelaku UKM sektor makan dan minuman memposisikan ulang produk-produk lama mereka yang sudah ada sebelumnya.

Tabel 5. Inovasi Produk

\begin{tabular}{lcc}
\hline \multicolumn{1}{c}{ Pernyataan } & TCR & Kategori \\
\hline $\begin{array}{l}\text { Kami seringkali } \\
\text { memperkenalkan produk- } \\
\text { produk baru. }\end{array}$ & $83 \%$ & Tinggi \\
$\begin{array}{l}\text { Kami mengembangkan fitur- } \\
\text { fitur produk baru. }\end{array}$ & $82 \%$ & Tinggi \\
$\begin{array}{l}\text { Kami memposisikan ulang } \\
\text { produk kami yang sudah ada. }\end{array}$ & $81 \%$ & Tinggi
\end{tabular}

\begin{tabular}{lcc}
\hline \multicolumn{1}{c}{ Pernyataan } & TCR & Kategori \\
\hline $\begin{array}{l}\text { Kami menggunakan produk- } \\
\text { produk baru untuk menembus } \\
\text { pasar sasaran }\end{array}$ & $84 \%$ & Sangat Tinggi \\
\hline
\end{tabular}

Menurut analisa penulis, produkproduk lama yang telah dijual oleh pelaku UKM pada sektor makanan dan minuman sebelumnya dan sudah tidak eksis lagi saat sekarang masih diposisikan ulang dan terdapat dalam menu penjualan, sekalipun itu sudah tidak lagi maksimal. Penulis juga beranggapan bahwa produk lama yang diposisikan ulang oleh pelaku UKM makanan dan minuman di Kota Padang ini, didasari oleh keyakinan para pelaku UKM bahwa pelanggan setia dengan beberapa produkproduk lama tersebut.

\section{PLS Output}

Analisis PLS yang dilakukan pada penelitian ini terbagi menjadi dua, yaitu analisis algorithm dan boostraping (Hult et al., 2015). Tabel 5 memperlihatkan bahwa setiap variabel yang diuji telah memenuhi prasyarat dan lulus uji validitas dan reliabilitas, karena memiliki nilai AVE $>0,5$, CA > 0,7, dan CR 0,7.

Sementara itu, nilai koefisien determinasi dari kinerja pasar sangat tinggi, karena melebihi 0,66. Hult et al. (2015) menyatakan bahwa nila $\mathrm{R}$-square diatas 0,66 mengindikasikan model yang sangat baik.

Hasil ini menjelaskan bahwa ketika ada permasalahan ataupun upaya untuk meningkatkan kinerja pasar UKM pada sektor makanan dan minuman di Kota Padang, maka hal pertama yang perlu diperhatikan adalah elemen-elemen inovasinya, karena kontribusi dari inovasi pada sektor ini sebesar $74,9 \%$, dan $25,1 \%$ lainnya dipengaruhi oleh faktorfaktor yang tidak diuji di penelitian ini.

Tabel 6. Validity, Reliability, dan R-Square

\begin{tabular}{|c|c|c|c|c|}
\hline & AVE & $\mathrm{CA}$ & CR & R Square \\
\hline KP & 0,747 & 0,915 & 0,937 & 0,749 \\
\hline IPm & 0,678 & 0,920 & 0,936 & \\
\hline IPs & 0,707 & 0,862 & 0,906 & \\
\hline IPk & 0,711 & 0,865 & 0,908 & 0,558 \\
\hline
\end{tabular}


Sedangkan pada inovasi produk, kontribusi inovasi proses dan pemasaran secara bersamaan sebesar 55,8\%. Artinya, jika ada permasalahan tentang keberlanjutan ataupun upaya untuk meningkatkan inovasi produk, maka 55,8 \% adalah bersumber dari inovasi pemasaran dan inovasi proses. Nilai koefisien determinasi tersebut juga mengindikasikan bahwa keterikan yang kuat dari antar elemen-elemen inovasi demi meningkatkan kinerja pasar.

Untuk melengkap uji validitas, maka perlu untuk mengetahui dan memeriksa hasil uji validitas diskriminannya. Prasyarat uji diskriminan yaitu nilai konstruk yang dituju harus lebih besar daripada nilai konstrukkonstruk sebelumnya dan memiliki nilai konstruk akhir diatas 0,7 (Hair et al., 2010). Alasan dari pemilihan nilai Fornell and Larcker criterion sebagai rujukan yaitu dikarenakan prasyarat dan hasil yang mudah dipahami oleh pembaca.

Tabel 7. Discriminant Validity

\begin{tabular}{lllll}
\hline & KP & IPm & IPs & IPk \\
\hline KP & 0,864 & & & \\
IPm & 0,724 & 0,823 & & \\
IPs & 0,728 & 0,766 & 0,841 & \\
IPk & 0,835 & 0,664 & 0,729 & 0,843 \\
\hline
\end{tabular}

Note: Fornell and Larcker Criterion

Berdasarkan hasil Tabel 6, maka dapat dinyatakan bahwa variabel-variabel yang diuji pada penelitian telah lolos uji validitas diskriminan. Dengan begitu, dalam analisis algorithm, penelitian ini secara keseluruhan telah dapat dilanjutkan pada tahap uji hipotesis.

Tabel 8. Hasil Hipotesis

\begin{tabular}{lcccc}
\hline & $(\mathrm{O})$ & S-Dev & T-Vs & P-Vs \\
\hline IPm $\rightarrow$ KP (H1) & 0,304 & 0,085 & 3,585 & 0,000 \\
IPm $\rightarrow$ IPk (H2) & 0,256 & 0,116 & 2,203 & 0,014 \\
IPs $\rightarrow$ IPk (H3) & 0,533 & 0,108 & 4,922 & 0,000 \\
IPk $\rightarrow$ KP (H4) & 0,633 & 0,079 & 7,976 & 0,000 \\
IPm $\rightarrow$ IPk $\rightarrow$ KP & & & \\
$($ H5) & 0,162 & 0,078 & 2,072 & 0,019 \\
\hline *Note: IPm = Inovasi Pemasaran, KP = Kinerja Pasar \\
IPs = Inovasi Proses, IPk = Inovasi Produk
\end{tabular}

Tabel 7 memperlihatkan keseluruhan hipotesis yang diuji dalam penelitian ini dinyatakan didukung. Sehubungan dengan hasil uji hipotesis tersebut, maka justifikasi terkait setiap pengaruh variabel bebas akan dijelaskan pada seksi selanjutnya.

\section{Inovasi Pemasaran Pada Kinerja Pasar}

Kinerja pasar dari pelaku UKM yang bergerak pada sektor makanan dan minuman di Kota Padang saat ini dihadapkan persaingan yang semakin kompetitif. Hal ini mengisyaratkan bahwa perlunya inovasi pemasaran untuk mempermudah pelanggan dalam menemukan produk-produk yang menarik dan terbaru, sehingga dapat meningkatkan minat beli mereka.

Inovasi pemasaran ditemukan berpengaruh signifikan dan positif pada kinerja pasar UKM pada sektor makanan dan minuman di Kota Padang. Disini, terindikasi adanya keinginan para pelaku UKM untuk meningkatkan kualitas hubungan dengan pelanggan, karena ekpektasi mereka yang semakin bertumbuh. Pelaku UKM yang mayoritasnya berusia dibawah 40 tahun memiliki antusiasme yang sangat tinggi dari untuk memperluas pasar dan cakupan promosi mereka demi meningkatkan volume penjualan secara berkelanjutan.

Hasil penelitian ini mendukung temuan sebelumnya dari Abdilahi et al. (2017), Aksoy (2017) dan Lee et al. (2016) yang menemukan bahwa inovasi pemasaran meningkatkan kekuatan persaingan dan kinerja pasar UKM. Usia serta kualitas pendidikan pelaku UKM untuk lebih maju dimasa digitalisasi telah mendorong mereka untuk lebih memanfaatkan social media, dan bekerja sama dengan e-commerce yang ada untuk mendukung mereka melakukan inovasi dalam pemasaran.

Grashuis and Dary (2019) juga menemukan bahwa penting melakukan inovasi pemasaran pada sektor usaha makanan dan minuman, dikarenakan kebiasaan atau perilaku kebanyakan orang yang menggunakan media social dalam membandingkan antara satu produk dan produk lainnya (Karjaluoto et al., 2015) dan ingin mengetahui manfaat dan khasiat dari apa yang akan mereka konsumsi (Steffen, 2017). 


\section{Inovasi Pemasaran pada Inovasi Produk}

Inovasi pemasaran ditemukan berpengaruh signifikan dan positif pada inovasi produk, dengan $t$-value 2,203 dan $p$ value 0,014 . Hal-hal yang mendasari temuan ini berkaitan dengan keyakinan para pelaku bahwa inovasi pemasaran memberikan dorongan pada permintaan inovasi produk saat sekarang. Penurunan pendapatan UKM pada sektor makanan dan minuman yang kurang dari Rp. 30.000.000 perbulannya, telah mendorong para pelaku UKM untuk menampilkan produk-produk yang inovatif dan memasarkannya dengan cara-cara yang inovatif. Sementara itu, mayoritas usia pelaku UKM pada rentang 21-40 tahun dan berkelamin perempuan, memiliki kecenderungan beraktifitas dan fokus dalam digitalisasi serta mengikuti tren.

Sharma et al. (2019) menyatakan bahwa trend terus berkembang menuju gaya hidup yang lebih sehat, keamanan pangan dan nilai yang lebih tinggi bagi konsumen. Misalnya, penggunaan bahan-bahan organic atau yang tidak mengandung lemak jahat dan kimia akan meningkatkan sifat fungsional produk makanan serta mengurangi ketergantungan pada bahan kimia yang berpotensi berbahaya bagi kesehatan pelanggan. Jadi, inovasi produk yang dilakukan oleh pelaku UKM di Kota Padang akan mendorong kepercayaan pelanggan atau calon pelanggan ketika inovasi pemasaran dilakukan.

Hasil penelitian ini mendukung beberapa penelitian yang menemukan hubungan positif dan pengaruh yang signifikan antara inovasi pemasaran dan inovasi produk (Aksoy, 2017; Anwar et al., 2020; Ramirez et al., 2018). Temuan ini membuktikan bahwa inovasi pemasaran memberdayakan penawaran produk yang lebih murah dan berkualitas lebih baik serta menghasilkan diversifikasi produk yang lebih tinggi, yang membantu pelaku UKM pada sektor makanan dan minuman untuk memperluas penawaran mereka. Dengan demikian, UKM makanan dan minuman di Kota Padang harus menggunakan metode baru dan ide-ide pemasaran yang inovatif untuk mempromosikan produk mereka yang tidak terkenal di pasar, karena inovasi pemasaran memberikan informasi dan dorongan untuk menghasilkan inovasi produk yang sangat baik.

\section{Inovasi Proses Pada Inovasi Produk}

Inovasi produk telah ditemukan secara signifikan dan positif dipengaruhi oleh inovasi proses dengan $t$-value 4,922 dan $p$ value 0,000 . Hasil ini mengindikasikan pentingnya melakukan inovasi pada prosesproses operasi untuk mempercepat inovasi produk. Usia pelaku yang notabene muda akan lebih sensitif dengan perkembangan dan persaingan, sehingga mengarahkan mereka untuk memanfaatkan teknologi sebaikbaiknya dalam efesiensi operasi, percepatan launching, serta akurasi pasar yang tinggi.

Inovasi proses terjadi melalui adaptasi peralatan yang dikembangkan di tempat lain untuk pengolahan makanan dan minuman. Oleh karena itu, membangun ikatan kolaboratif dapat memfasilitasi inovasi proses untuk mempercepat inovasi produk yang membuatnya menjadi lebih efisien. Sebagian besar inovasi produk dalam industri makanan bersifat inkremental daripada radikal (Purba et al., 2018). Ini mungkin terkait dengan apa yang disebut perbedaan ekpektasi dari masing-masing tempat yang disebabkan oleh perilaku konsumen yang konservatif terhadap produk makanan dan minuman baru.

Temuan ini mendukung temuan Lita et al. (2018) Fortuin dan Omta, (2009) dan Triguero et al. (2018). Untuk mencapai inovasi produk yang diminati pasar, pelaku UKM harus memperhatikan inovasi prosesnya, karena menyangkut efisiensi dan kecepatan waktu dalam proses produksi dan waktu yang tepat dalam merilis produk ke pasar sasaran. Inovasi dalam industri makanan dan minuman adalah proses yang kompleks dan dapat melibatkan banyak aktor berbeda (Enzing et al., 2011), mulai dari pengembangan bahan-bahan baru hingga formulasi untuk produk-produk baru, serta peningkatan metode pengawetan makanan dan minuman hingga cara pengemasan baru (Khan et al., 2014). 


\section{Inovasi Produk pada Kinerja Pasar}

Inovasi produk ditemukan berpengaruh signifikan dan positif pada kinerja pasar di sektor UKM makanan dan minuman. Hasil ini memperjelas bahwa sektor makanan dan minuman sangat memerlukan inovasi terhadap produk-produknya untuk mencapai kinerja pasar yang maksimal. Adanya keinginan yang tinggi dari para pelaku UKM di Kota Padang untuk menembus pasar sasaran melalui inovasi produk, serta terindikasinya keyakinan mereka jika melakukan inovasi produk maka penjualan akan meningkat.

Efek negatif Covid-19 yang sangat berdampak pada penurunan penjualan UKM sektor makanan dan minuman juga menjadi alasan para pelaku untuk mempercepat pemulihan usahanya melalui inovasi. Para pelaku UKM yang notabene masih muda dan mayoritas beroperasi dengan modal pribadi ataupun modal keluarga, secara psikologis lebih memiliki keberanian dalam melakukan hal-hal yang baru untuk menjaga eksistensi usaha mereka, karena responden mengakui bahwa inovasi yang dilakukan selama ini telah menarik banyak pelanggan baru.

Temuan penelitian mendukung studi sebelumnya dari Abdilahi et al. (2017); Adnan dan Ahmad (2015) dan (Bresciani, 2017), dimana produk-produk yang dihasilkan oleh UKM terutama di sektor makanan dan minuman sangat diminati oleh pasar ketika ditawarkan pembaharuan dan kreatifitas produk. Yehorycheva et al. (2020) juga menemukan bahwa inovasi memberikan jaminan untuk kinerja pasar UKM. Oleh karena itu, penting mempertahankan inovasi produk tanpa mengabaikan aspek-aspek yang berhubungan dengan higenitas dan kesehatan produk, karena produk-produk makanan dan minuman lebih sensitif dari pada produkproduk lainnya.

\section{Mediasi Inovasi Produk Dalam Inovasi Pemasaran Pada Kinerja Pasar}

UKM sektor makanan dan minuman lebih fokus pada inovasi inkremental dibandingkan dengan inovasi radikal karena sifatnya yang terus bertumbuh (Baregheh et al., 2012). Dalam hal karakteristik inovasi, UKM sektor makanan dan minuman yang diteliti setuju bahwa mereka biasanya berkomitmen untuk sebagian besar dari berbagai faktor yang mempengaruhi orientasi inovasi, seperti menemukan teknik penjualan yang baru dan memberikan perubahan baru pada program pemasaran. Namun, yang paling penting diantaranya adalah komitmen untuk mendorong ide-ide baru, dan menumbuhkan produk yang inovatif untuk memperbanyak pelanggan mereka.

Inovasi produk ditemukan sangat penting dalam konteks pemasaran karena memungkinkan pemasar untuk lebih kreatif. Hasil penelitian ini menemukan bahwa peran atau kontribusi dari inovasi produk secara signifikan memberikan efek mediasi dalam hubungan antara inovasi pemasaran dan kinerja pasar secara parsial dengan total efek sebesar $34,76 \%$. Hasil ini juga menyiratkan bahwa inovasi produk berperan sebagai bukti dari kebenaran inovasi pemasaran. Selain itu, peran inovasi produk telah meningkatkan kepercayaan pelanggan UKM sektor makanan dan minuman di Kota Padang ketika mereka melihat pemasaran yang inovatif dari para pelaku UKM.

Aktifitas yang telah terjadi ini memperjelas bahwasanya temuan penelitian ini telah disadari sebelumnya oleh pelaku UKM makanan dan minuman di Kota Padang yang dipicu oleh tingkat persaingan yang tinggi serta banyaknya pelaku UKM makanan dan minuman yang berpendidikan sarjana 1 dan masih relatif muda dengan rentang usia 21-30 tahun, dimana masih sangat aktif dalam penggunaan teknologi dan media sosial.

Inovasi produk dan pemasaran pada pelaku UKM makanan dan minuman akan menghasilkan pertumbuhan produktivitas yang jauh lebih cepat karena menggunakan kombinasi inovasi produk dan pemasaran, yang mengarahkan pada kinerja pasar yang maksimal dan perluasan pangsa pasar. Hasil penelitian ini berkaitan dengan penelitian Sharma et al. (2019) yang menemukan bahwa peran mediasi inovasi produk makanan dan minuman telah mendorong aktivitas pemasaran untuk mencapai segmen yang 
lebih luas. Hasil ini juga mendukung studi Aksoy (2017) yang menemukan inovasi produk penting dalam konteks inovasi pemasaran karena menarik banyak pelanggan baru dengan menjanjikan nilai superior.

Putri dan Yasa (2018) menyatakan dorongan dari perubahan kemasan, inovasi kearah organik, serta penyajian yang menarik berpengaruh signifikan dalam peningkatan kinerja pasar pelaku UKM sektor makanan dan minuman. Sehunbungan denga itu, maka untuk mendorong produk yang inovatif dan rencana bisnis, ketika produk sepenuhnya dikembangkan dan siap memasuki pasar, beberapa tahapan seperti memulai pengenalan produk melalui komunikasi inovasi, inovasi terhadap promosi seperti konten-konten yang menarik, teknik penjualan, program pemasaran, menawarkan kemudahan pesanan, dan membangun hubungan baik antara konsumen dan penjual ditemukan sebagai cara yang signifikan untuk meningkatkan volume penjualan dan pelebaran pasar sasaran.

Harjadi et al. (2020) juga menemukan bahwa inovasi produk pada sektor makanan mempengaruhi keunggulan bersaing pelaku UKM yang mengarahkannya pada kinerja pasar yang optimal (Harjadi et al., 2020), akibat dorongan inovasi pemasaran (Saunila, 2017). Inovasi pemasaran pada sektor makanan tidak dapat diukur hanya dan lebih mengutamakan penerapan teknologi, karena Covid-19 terbukti meningkatkan sensitifitas terkait bagaimana orang-orang mempercayai dan mengerti setiap komunikasi bisnis (Hidayat et al., 2021), yang mengarahkan pilihan mereka pada eksperimen diri sendiri untuk makanan dan minuman ketika mereka dirumah (Ji \& Prentice, 2021), karena inovasi tidak sepenuhnya menyangkut Research and Development (Kemp, 2013; López et al., 2003).

\section{Kesimpulan}

Identifikasi dan dugaan masalah yang ditemukan di lapangan, menjelaskan bahwa tingkat kepentingan para pelaku UKM makanan dan minuman semakin mengarah pada inovasi, baik itu inovasi tentang pemasaran, proses, maupun inovasi tentang produk, demi mencapai kinerja pasar yang maksimal.

Temuan penelitian menunjukkan bahwa seluruh variabel yang diuji berpengaruh signifikan dan positif. Ini mengindikasikan ketepatan alat ukur dan pemilihan variabel dalam menyimpulkan fenomena dilapangan. Dengan rincian; Inovasi pemasaran berpengaruh positif dan signifikan pada kinerja pasar, dan ketika dimediasi oleh inovasi produk, hubungan inovasi pemasaran pada kinerja pasar juga signifikan, dengan total efek mediasi sebesar 34,76\%. Sementara itu, pengaruh positif dan signifikan juga ditemukan pada variabel inovasi proses pada inovasi produk, dan inovasi produk pada kinerja pasar.

Keterbatasan penelitian ini, pada justifikasi hasil yang hanya fokus pada UKM makanan dan minuman sehingga perlu diperluas untuk sektor-sektor yang lain. Penelitian ini hanya fokus pada variabel inovasi dan kinerja pasar, perlu diteliti dampak variabel lain terhadap kinerja serta tidak hanya menggunakan ukuran kinerja pasar saja.

\section{DAFTAR PUSTAKA}

Abdilahi, M. H., Hassan, A. A., \& Muhumed, M. M. (2017). The Impact of Innovation on Small and Medium Enterprises Performance: Empirical Evidence from Hargeisa, Somaliland. International Journal of Academic Research in Business and Social Sciences, 7(8). https://doi.org/10.6007/ijarbss/v7-i8/3202

Adnan, Z. S., \& Ahmad, H. (2015). Innovation in Malaysian Food and Beverage Manufacturing SME. Khon Kaen Agr. J. 43 Suppl, 1(8), 7196.

Ahmadi, H., \& O'Cass, A. (2016). The role of entrepreneurial marketing in new technology ventures first product commercialisation. Journal of Strategic Marketing, 24(1), 47-60. https://doi.org/10.1080/0965254X.2015.103 5039

Aksoy, H. (2017). How do innovation culture, marketing innovation and product innovation affect the market performance of small and medium-sized enterprises 
(SMEs)? Technology in Society, 51, 133141.https://doi.org/10.1016/j.techsoc.2017. 08.005

Anwar, M., Zaman Khan, S., \& Ali Shah, S. Z. (2020). A Study of the Relationship Between Innovation and Performance Among NPOs in Pakistan. Journal of Social Service Research, 46(1), 26-40. https://doi.org/10.1080/01488376.2018.151 6265

Baregheh, A., Rowley, J., Sambrook, S., \& Davies, D. (2012). Innovation in food sector SMEs. Journal of Small Business and Enterprise Development, 19(2), 300321.https://doi.org/10.1108/146260012112 23919

Biégas, S. (2018). Marketing Innovation Capacity and Firm Performance in Brazilian Clothing Industries. Revista Brasileira de Estratégia, 11(3), 343-355. https://doi.org/10.7213/rebrae.11.003.AO03

Bresciani, S. (2017). Open, networked and dynamic innovation in the food and beverage industry. British Food Journal, 119(11), 2290-2293. https://doi.org/10.1108/BFJ-08-2017-0458

Byrne, B. M. (2009). Structural Equation Modeling With AMOS: Basic Concepts, Applications, and Programming, Second Edition (Multivariate Applications Series) 2nd Edition. Routledge.

Chen, Y. (2006). Marketing innovation. Journal of Economics and Management Strategy, 15(1), 101-123. https://doi.org/10.1111/j.15309134.2006.00093.x

Chen, Y. (2019). Marketing Innovation. (1). https://doi.org/10.1111/j.15309134.2006.00093.x

Chi, Z., \& Seock-jin, H. (2017). Guanxi Culture : How it Affects the Business Model of Chinese Firms. In The China Business Model. https://doi.org/10.1016/B978-0-08100750-1.00002-4

Desara, T., Verinita, V., Maruf, M., \& Hidayat, T. (2021). Enhancing Repurchase Intention in Retail : the Role of Customer Satisfaction, Service Quality, and Product Assortment. Enrichment Journal of Management, 12(1), 325-329.

Elgebali, M. (2019). Marketing innovation in service smes a study in the egyptian food and beverage industry. International Journal of Entrepreneurship, 23(3), 4675.
Enzing, C., Pascucci, S., Janszen, F., \& Omta, O. (2011). Role of open innovation in the shortand long-term market success of new products: Evidence from the Dutch food and beverages industry. Journal on Chain and Network Science, 11(3), 235250.https://doi.org/10.3920/JCNS2011.x19 7

Erdin, C., \& Ozkaya, G. (2020). Contribution of small and medium enterprises to economic development and quality of life in Turkey. Heliyon, 6(2), e03215. https://doi.org/10.1016/j.heliyon.2020.e032 15

Fortuin, F. T. J. M., \& Omta, S. W. F. (2009). Innovation drivers and barriers in food processing. British Food Journal, 111(8), 839-851. https://doi.org/10.1108/0007070091098095 5

Games, D., Soutar, G., \& Sneddon, J. (2020). Personal values and SME innovation in a Muslim ethnic group in Indonesia innovation. Journal of Entrepreneurship in Emerging Economies, 2053-4604. https://doi.org/10.1108/JEEE-01-2020-0008

Garcia Martinez, M., \& Briz, J. (2000). Innovation in the Spanish food \& drink industry. International Food and Agribusiness Management Review, 3(2), 155-176. https://doi.org/10.1016/s10967508(00)00033-1

Gotteland, D., Shock, J., \& Sarin, S. (2020). Strategic orientations, marketing proactivity and firm market performance. Industrial Marketing Management, (October 2016), 111.

https://doi.org/10.1016/j.indmarman.2020.0 3.012

Grashuis, J., \& Dary, S. (2019). Patented Innovation and Firm Value in the U.S. Food and Drink Industry: The Economic Importance of High-Quality Product Innovation. Journal of Agricultural and Food Industrial Organization, 17(2), 1-14. https://doi.org/10.1515/jafio-2017-0002

Grimpe, C., Sofka, W., Bhargava, M., \& Chatterjee, R. (2017). R\&D, Marketing Innovation, and New Product Performance: A Mixed Methods Study. Journal of Product Innovation Management, 34(3), 360-383. https://doi.org/10.1111/jpim.12366

Hair, J. F., Black, W. C., Babin, B. J., \& Anderson, R. E. (2010). Multivariate Data 
Analysis (7th ed.). New York: Pearson Prentice Hall.

Hair, J. F., Hult, G. T. M., Ringle, C. M., \& Sarstedt, M. (2017). A Primer on Partial Least Squares Structural Equation Modelling (PLS-SEM) (2nd ed.). Thousand Oaks, California: SAGE Publications.

Hajduova, Z., Hajduova, Z., Peráček, T., \& Hurajová, J. C. (2021). “ Determinants of innovativeness of Slovak SMEs ." 9381. https://doi.org/10.21511/ppm.19(1).2021.17

Hamali, S. (2015). The Effect of Entrepreneurial Marketing on Business Performance : Small Garment Industry in Bandung City , Indonesia. Developing Country Studies, 5(1), 24-30. https://doi.org/10.1016/j.nbd.2003.11.028

Hidayat, T., Fahmy, R., Sari, D. K., Mergeresa, F., \& Fernando, Y. (2021). COVID-19 Outbreak Effect on Leadership, Job Satisfaction, And Turnover Intention: A Mediating Model of Indonesian Banking Sector. International Journal of Industrial Management, $\quad 10(1), \quad 113-128$. https://doi.org/10.1.2021.6011

Iddris, F. (2019). Innovation capability and product innovation performance: the case of low-tech manufacturing firms. European Business Review, 31(5), 646-668. https://doi.org/10.1108/EBR-12-2016-0159

Ji, C., \& Prentice, C. (2021). Linking transactionspecific satisfaction and customer loyalty The case of casino resorts. Journal of Retailing and Consumer Services, 58 (June 2020),

102319 . https://doi.org/10.1016/j.jretconser.2020.10 2319

Kahn, K. B. (2018). Understanding innovation. Business Horizons, 61(3), 453-460. https://doi.org/10.1016/j.bushor.2018.01.01 1

Karjaluoto, H., Mustonen, N., \& Ulkuniemi, P. (2015). The role of digital channels in industrial marketing communications. Journal of Business and Industrial Marketing, $\quad 30(6), \quad 703-710$. https://doi.org/10.1108/JBIM-04-20130092

Kemp, S. E. (2013). Consumers as part of food and beverage industry innovation. In Open Innovation in the Food and Beverage Industry.https://doi.org/10.1533/978085709 7248.2.109

Khan, R. S., Grigor, J. V., Win, A. G., \& Boland, M. (2014). Differentiating aspects of product innovation processes in the food industry: An exploratory study on New Zealand. British Food Journal, 116(8), 1346-1368. https://doi.org/10.1108/BFJ-042013-0094

Lee, K., Yoo, J., Choi, M., Zo, H., \& Ciganek, A. P. (2016). Does external knowledge sourcing enhance market performance? Evidence from the Korean manufacturing industry. PLOS ONE, 11(12), 1-19. https://doi.org/10.1371/journal.pone.01686 76

Lestari, E. R., Ardianti, F. L., \& Rachmawati, L. (2018). Firm performance model in small and medium enterprises (SMEs) based on learning orientation and innovation. IOP Conference Series: Earth and Environmental Science, 131(1). https://doi.org/10.1088/17551315/131/1/012027

Lita, R. P., Meuthia, M., Faisal, R. F., \& Surya, S. (2018). SME's innovative performance in Indonesia: The linkage between innovation culture and production performance. International Journal of Supply Chain Management, 7(4), 242-253.

López, N., Montes-Peón, J. M., \& VázquezOrdás, C. (2003). Innovation in the Spanish food and beverage industry: An integrated approach. International Journal of Biotechnology, 5(3-4), 311-333. https://doi.org/10.1504/ijbt.2003.004100

Maisont, P., Taiphapoon, T., Chandrachai, A., \& Sinthupinyo, S. (2020). New Product Development Co Creation Process: a Thai Case of Micro Community Enterprises of Non-Food Herbal Products and R\&D Government Organizations. Academy of Entrepreneurship Journal, 26(4), 1-17.

Ndiaye, N., Abdul Razak, L., Nagayev, R., \& Ng, A. (2018). Demystifying small and medium enterprises' (SMEs) performance in emerging and developing economies. Borsa Istanbul Review, 18(4), 269-281. https://doi.org/10.1016/j.bir.2018.04.003

Oh, C., Cho, Y., \& Kim, W. (2015). The effect of a firm's strategic innovation decisions on its market performance. Technology Analysis and Strategic Management, 27(1), 39-53. https://doi.org/10.1080/09537325.2014.945 413

Pratama, Z. P., Sari, D. K., Games, D., \& Hidayat, T. (2021). Covid-19 Pandemic: Enhancing Customer Loyalty To Traditional Market 
Existence. Enrichment: Journal of Management, 12(1), 152-157.

Putri, N. K. N., \& Yasa, N. N. K. (2018). Peran Inovasi Produk Memediasi Orientasi Pasar Terdahap Kinerja Pemasaran (Studi pada Usaha Mikro, Kecil dan Menengah Pie Susu di Kota Denpasar). Matrik: Jurnal Manajemen, Strategi Bisnis Dan Kewirausahaan, 111 . https://doi.org/10.24843/matrik:jmbk.2018. v12.i02.p03

Rahmawati, S., Darsono, D., \& Setyowati, N. (2019). Faktor-Faktor yang Mempengaruhi Kinerja Pemasaran pada Usaha Mikro Kecil dan Menengah Pangan Olahan di Kota Surakarta. Jurnal Ekonomi Pertanian Dan Agribisnis, 3(2), 325-335. https://doi.org/10.21776/ub.jepa.2019.003.0 2.9

Ramirez, F. J., Parra-Requena, G., Ruiz-Ortega, M. J., \& Garcia-Villaverde, P. M. (2018). From external information to marketing innovation: the mediating role of product and organizational innovation. Journal of Business and Industrial Marketing, 33(5), 693-705. https://doi.org/10.1108/JBIM-122016-0291

Reinartz, W., Haenlein, M., \& Henseler, J. (2009). An Empirical Comparison of the Efficacy of Covariance-Based and Variance-Based SEM. International Journal of Research in Marketing, 26, 332-344. https://doi.org/10.1016/j.ijresmar.2009.08.0 01

Roucan-Kane, M., Gray, A. W., \& Boehlje, M. D. (2011). Approaches for selecting product innovation projects in U.S. Food and agribusiness companies. International Food and Agribusiness Management Review, 14(4), 51-68.

Saunila, M. (2017). Understanding innovation performance measurement in SMEs. Measuring Business Excellence, 21(1), 116. https://doi.org/10.1108/MBE-01-20160005

Seyfettinoğlu Ü K. (2016). Analysis of Relationships between Firm Performance and Open Innovation Strategies and Stages in the Turkish Food and Beverage Industry. New Medit, 15(1), 42-52.

Sharma, P., Davcik, N. S., \& Pillai, K. G. (2019). Product Innovation as a Mediator in the Impact of R\&D Expenditure and Brand Equity on Marketing Performance. Journal of Business Research, 102,(351), 49-58. https://doi.org/10.1016/j.jbusres.2016.03.07 4

Steffen, A. (2017). Exploring the Benefits of Employing Market Insights and Consumer Trends in Food Product Innovation: A Case Study from Germany. In Case Studies in the Traditional Food Sector: A volume in the Consumer Science and Strategic Marketing series. https://doi.org/10.1016/B978-0-08101007-5.00008-7

Sugiyono. (2010). Metode penelitian kuantitatif, kualitatif, dan R \& D. In Metode penelitian kuantitatif, kualitatif, dan $R \& D$. Alfabeta.

Tomas M. Hult, Sarstedt, M., \& Ringle, C. M. (2015). A primer on partial least squares structural equation modeling (PLS-SEM). International Journal of Research \& Method in Education, 38(2), 220-221. https://doi.org/10.1080/1743727x.2015.100 5806

Triguero, A., Fernández, S., \& Sáez-Martinez, F. J. (2018). Inbound open innovative strategies and eco-innovation in the Spanish food and beverage industry. Sustainable Production and Consumption, 15, 49-64. https://doi.org/10.1016/j.spc.2018.04.002

Tutar, H., Nart, S., \& Bingöl, D. (2015). The Effects of Strategic Orientations on Innovation Capabilities and Market Performance: The Case of ASEM. Procedia - Social and Behavioral Sciences, 207, 709719. https://doi.org/10.1016/j.sbspro.2015.10.14 4

Usmed, D. C., Syafrizal, S., Alfitman, A., Yuliani, F., \& Hidayat, T. (2021). Customer Loyalty Research: The Cases of Existing ECommerce Platforms. Enrichment: Journal of Management, 12(1), 499-504.

Werker, C. (2003). Innovation, market performance, and competition: Lessons from a product life cycle model. Technovation, 23(4), 281-290.

Yehorycheva, S., Fysun, I., Hudz, T., Palchuk, O., \& Boiko, N. (2020). Innovations in the insurance market of a developing country: Case of Ukraine. Investment Management and Financial Innovations, 17(4), 175-188. https://doi.org/10.21511/imfi.17(4).2020.17

Zhang, J. A., Garrett-Jones, S., \& Szeto, R. (2013). Innovation capability and market performance: The moderating effect of industry dynamism. International Journal of Innovation Management, 17(2), 1-35. 